\title{
Obituary: Constantinos Karaliotas
}

Constantinos Karaliotas died on Saturday, 24 February 2018, after an illness lasting several months. He was for many years Director of the $2^{\text {nd }}$ Surgical Department and the Surgical Oncology Unit of the Hellenic Red Cross Hospital.

Constantinos Karaliotas was born on 11 October 1947 in Siatista in the Prefecture of Kozani. He grew up and completed his high school studies in Larisa. He then studied at the Medical School of the University of Athens, and he completed his specialty training in general surgery at the Hellenic Red Cross Hospital "Korgialeneio-Benakeio".

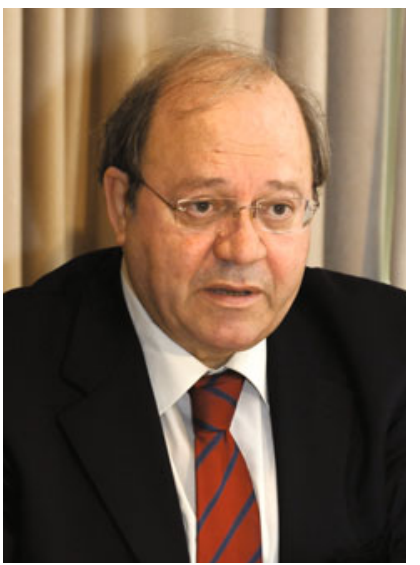

on to the next president of the society a substantial balance of funds, a historical record.

He was Secretary General of the College of Greek Surgeons, and he participated in several important Ministry of Health committees.

He participated in over 250 Greek and international conferences and seminars and followed a large number of educational events. He made a great contribution to the educational section of the Hellenic Surgical Society, and for 15 years, from 1992 to 2006 he was a member of the Educational Council of the society. In support of the

After receiving his doctorate from the University of Athens, he continued working at the Hellenic Red Cross Hospital, firstly as internal assistant to the Director, Evangelos Papaevangelos, then in the posts of junior and senior registrar, and in 1996 he was appointed head of the Surgical Oncology Unit. In 2000 he became Director of the $2^{\text {nd }}$ Department of Surgery of the Hellenic Red Cross Hospital.

He regularly went for post-graduate training in Germany, Austria and England. His activity in the scientific and writing aspects of his career was substantial, and he delivered over 200 papers at both Greek and international medical conferences.

He published over 60 scientific articles in renowned Greek and foreign medical journals. He also contributed a large number of chapters for scientific publications, and wrote and edited 6 books, the most important of which was "Liver and Biliary Tract Surgery", with co-editors Christoph Broelch from Germany and Habib Nagy from England. His main areas of surgical interest were the biliary tract and the pancreas, and neuroendocrine tumors, but his publications covered the full range of general surgery.

He was a member of 15 Greek and international scientific societies, and for 15 years served on the Executive Council of the Hellenic Surgical Society and was its President from 2007-2008. His presidency was notable, and during his term of office he made a concerted effort to put in order the finances of the Hellenic Surgical Society, which at that time were causing concern. Not only did he succeed in this task, but the Society at that time acquired the office space in Artis St., which it still occupies, and he managed to pass society's efforts for the continuing education of surgeons, he delivered more than 170 relevant addresses, presided over at least 140 round table discussions, and was on the organizing committee of countless conferences and seminars and other scientific events.

For many years he served as editor of the Journal of the Hellenic Surgical Society and during his term he succeeded in raising its standard to become an internationally recognized scientific journal.

He served as Secretary General of the $23^{\text {rd }}$ Panhellenic Surgical Conference and International Surgical Forum 2002. $\mathrm{He}$ was President of the highly successful $25^{\text {th }}$ Panhellenic Surgical Conference and International Surgical Forum 2006, which became the exemplification of the conference, not only of high scientific prestige, but also of impeccable administrative and financial management, which subsequently became the blueprint for all future conferences.

It was my honor and good fortune to meet Constantinos Karaliotas 23 years ago when I was appointed registrar in the $2^{\text {nd }}$ Department of Surgery of the Hellenic Red Cross Hospital. He was a brilliant man with an exceptional education and with a strong personality and extremely high ideals and goals. He was hard-working all his years and dedicated to medical science, and in particular to surgery and to the ailing patient. He was a top-class teacher and speaker, and all who had the good fortune to train in his department are greatly in his debt.

For his patients he was not just their surgeon, but he insisted on treating each patient as an entity. Every day we were witness to his deep scientific knowledge and his 
powers of analysis in confronting challenging diagnostic problems. Constantinos Karaliotas, beyond being a good surgeon was an unmatched clinician. Throughout the entire process of dealing with a patient he sought perfection, but most importantly he possessed good medical acumen and concern for every patient, and he always endeavored to exercise the principle "metron ariston" "all in good measure" in his surgical practice. Innumer- able patients owe their good health, or even their lives to the realistic medical judgement and the surgical skill of Constantinos Karaliotas.

He will live for ever in our memory.

\section{Pantelis Brotzakis}

Director, $2^{\text {nd }}$ Department of Surgery

New Hellenic Red Cross Hospital 